\title{
(6) OPEN ACCESS \\ Heat-related chronic kidney disease mortality in the young and old: differing mechanisms, potentially similar solutions?
}

\section{Tomás Ó Flatharta, ${ }^{1}$ Aidan Flynn, ${ }^{2}$ Eamon C Mulkerrin ${ }^{3}$}

10.1136/bmjebm-2018-110971

${ }^{1}$ Department of Geriatric Medicine, University Hospital Galway, Galway, Ireland ${ }^{2}$ Department of Cardiology, Portiuncula University Hospital, Galway, Ireland ${ }^{3}$ Clinical Research Facility, Department of Medicine, National University of Ireland, Galway, Ireland

Correspondence to: Dr Tomás ó Flatharta, Department of Geriatric Medicine, University Hospital Galway, Galway H91 YR71, Ireland; t.oflatharta3@gmail. com

Check for updates

(- Author(s) (or their employer(s)) 2019. Re-use permitted under CC BY-NC. No commercial re-use. See rights and permissions. Published by BMJ.

To cite: Ó Flatharta T,

Flynn A, Mulkerrin EC. BMJ

Evidence-Based Medicine

2019;24:45-47.
Global warming is the single biggest threat to the future of the planet according to World Health Organisation. ${ }^{1}$ Climate change has contributed to higher rates of weather-related disasters over the last 10 years, including exposure to heatwaves. ${ }^{2}$ An increased prevalence of chronic kidney disease (CKD)-related mortality in young people who do not have the usual risk factors for the same has raised concern. The problem is particularly concentrated in areas such as Central America, India, Sri Lanka and Egypt, ${ }^{3}$ where young working men are exposed to excessive heat on a regular basis. This is sometimes dubbed Mesoamerican nephropathy or CKD of unknown origin (CKDu). Working indoors, which affects more female workers, including kitchen work with ovens, smelters and steel manufacturing are also implicated. ${ }^{4}$ Approximately $40 \%$ of the world's population inhabit areas subject to excessive heat throughout the year. Increasing prevalence of early-onset CKD has been noted worldwide, with El Salvador, in particular, recording the highest mortality rates. ${ }^{5}$

Meanwhile, CKD is emerging as a leading cause of mortality particularly in patients suffering from hypertension, diabetes mellitus and obesity. Worldwide, kidney disease is now reported as the 12th most common cause of death. ${ }^{6}$ While debate persists regarding the diagnosis and actual prevalence of CKD in those of advanced age, the majority of these patients are derived from the older age groups. ${ }^{7}$ Moreover, age-related reductions in renal reserve, plasma renin and aldosterone responses, glomerular filtration rate, as well as a predisposition to hyperkalaemia and haemoconcentration with hypernatraemia render older patients particularly susceptible to kidney injury and death when exposed to excessive heat. ${ }^{8}$ Other particularly vulnerable demographic subgroups include young children, disabled, isolated individuals and those who are socioeconomically disadvantaged. ${ }^{10}$

The possible mechanisms of the escalation in heat-related kidney failure-associated mortality in younger patients have not been fully elucidated. First, in a hot environment, increased insensible loss of body water and salt occurs. With prolonged heat exposure this leads to substantial fluid deficit which, if not replaced, may result in vasoconstriction and associated kidney injury. ${ }^{11}$ Moreover, with exertion in a state of chronic dehydration, subclinical rhabdomyolysis can occur due to chronic low-grade muscle injury, which can in turn also contribute to hyperuricaemia. ${ }^{12} 13$ This has been postulated to lead to glomerular hypertension and renal tubular injury. A pilot study performed on sugar cane workers in El Salvador demonstrated higher mean end-of-work serum levels of uric acid versus morning levels ( $428 \mu \mathrm{mol} / \mathrm{L}$ vs. $387 \mu \mathrm{mol} / \mathrm{L}$ ), with the vast majority demonstrating concurrent glomerular filtration rates $<60 \mathrm{~mL} / \mathrm{min} .{ }^{13}$ Resultant activation of the aldose reductase pathway within the kidney leads to increased levels of glucose and fructose. Fructose is then metabolised by fructokinase in the proximal tubule, which can lead to inflammation and fibrosis of the renal parenchyma as evidenced by Roncal-Jimenez et al., who demonstrated that mice without fructokinase were spared renal injury despite similar exposure to dehydration. ${ }^{14}$

The aetiology of this enhanced susceptibility to CKD appears to be multifactorial. ${ }^{15}$ For example, water 'hardness' may play a role. With high levels of calcium, magnesium and other metal cations, endemic areas with harder water in Sri Lanka correlate positively with those areas where CKDu is most prevalent. ${ }^{16}$ It is suggested that these cations can combine with substances in herbicides such as glyphosate. Glyphosate is an aminophosphonic acid analogue of the natural amino acid, glycine, which can be absorbed by inhalation, transdermally, or ingested either in food sprayed by herbicide or contaminated water supplies. ${ }^{16}{ }^{17}$ A study of 500 species of juvenile Clarias gariepinus fish which were fed with commercial pellets containing glyphosate demonstrated tissue evidence of renal necrosis and degenerated kidney tubules versus control fish without toxicant exposure. ${ }^{18}$

A recently published systematic review and meta-analysis of epidemiological studies on CKDu suggested positive associations with male gender, family history of CKD, water intake and lowland altitude. ${ }^{19}$ Meanwhile, in a cross-sectional study of sugar cane workers, Kupferman et al. reported that reduction of kidney function occurred commonly and almost half of those affected had CKD after 1 year. $^{20}$ Moreover, in a longitudinal study examining rates of decline of kidney function in high-risk populations for $\mathrm{CKDu}$, rapid decline occurred more commonly in men and was associated with outdoor agricultural work and lack of shade during work breaks. ${ }^{21}$

It is difficult to identify consistent risk factors isolated to affected areas but poorer economic areas generally do not provide equal access to healthcare, clean water, toilet facilities (with particularly female workers drinking less to avoid the need to urinate while working), and appropriate screening or diagnostics. ${ }^{4}$ 
Increased exposure of new populations to heat stress appears inevitable beyond the borders of currently identified countries, thus further enhancing the numbers at risk of CKD. Furthermore, in the presence of traditional risk factors for CKD, such as hypertension and diabetes mellitus, with associated increased rates of ischaemic heart disease, it is reasonable to assume that the increase in heat stress will result in further increases in mortality. Indeed, increased rates of heat-related myocardial infarction have already been reported in a cross-sectional study. ${ }^{22}$

Prevention is the best approach to addressing heat-related CKD-associated mortality. In older patients, this includes anticipatory implementation of simple measures such as maintenance of adequate fluid intake combined with minimising insensible loss using tepid sponging and relocating affected people to a cooler environment. Adjusting doses of medications such as diuretics, monitoring electrolytes and renal function, followed by early intervention to optimise electrolyte abnormalities will minimise progression to acute kidney injury. Regional heat plans and robust social programmes are helpful. ${ }^{9}$ In previous heatwaves, a report indicates that those people who met in public places had less morbidity and mortality than those who retreated indoors. ${ }^{23}$

Recent evidence indicates that implementing similar basic interventions in younger susceptible individuals, such as provision of portable water reservoirs, scheduled rest periods and mobile shaded tents to sugar cane workers, resulted in improvements in markers of dehydration and increased GFR. ${ }^{24}{ }^{25}$ However these fundings derived from small studies, with many methodological problems and thus lacks external validity. Guidelines recommend replacing fluid frequently when working in conditions that may lead to heat stress, for example, $250 \mathrm{~mL}$ water every $20 \mathrm{~min}$ with or without weight monitoring. ${ }^{26}$ Other interventions such as self-monitoring of early morning body weight, urine colour and thirst perception lack evidence. Education of workers regarding heat illness risks and preassessment of workers' serum creatinine levels may highlight at-risk individuals, but workers may avoid such testing for fear of resultant loss of income. Employers need education to emphasise that time lost with regular hydration breaks should result in increased productivity, less illnesses, workplace accidents and absenteeism.

While the mechanisms of heat-related kidney disease may differ between young and older individuals, simple anticipatory interventions could ameliorate deleterious renal consequences for all age groups.

Contributors TÓF: first author, wrote the first, subsequent and final drafts, as well as background reading/review of prior research. AF: second author, reviewed all drafts and edits, made edits and further review of the subject. ECM: third author, formed the idea and theory, reviewed and edited the drafts, further reading into the subject.

Competing interests None declared.

Patient consent Not required.

Provenance and peer review Not commissioned; externally peer reviewed.

Open access This is an open access article distributed in accordance with the Creative Commons Attribution Non Commercial (CC BY-NC 4.0) license, which permits others to distribute, remix, adapt, build upon this work non-commercially, and license their derivative works on different terms, provided the original work is properly cited, appropriate credit is given, any changes made indicated, and the use is non-commercial. See: http://creativecommons.org/licenses/by-nc/4.0/.

\section{References}

1. World Health Organisation. Launch of special initiative to address climate change impact on health in Small Island Developing States. Bonn: World Health Organisation, 2017.

2. Centre for Research on the Epidemiology of Disasters. The human cost of weather-related disasters: 1995-2015. United Nations Office for Disaster Risk Reduction. 2015 https://www.unisdr.org/2015/docs/climatechange/ COP21_WeatherDisastersReport_2015_FINAL.pdf (accessed 20 Mar 2018).

3. Dyer 0. CDC will explore kidney failure epidemic among agricultural workers. BMJ 2014;348:g3385.

4. Nerbass FB, Pecoits-Filho R, Clark WF, et al. Occupational heat stress and kidney health: from farms to factories. Kidney Int Rep 2017;2:998-1008.

5. Ramirez-Rubio 0, McClean MD, Amador JJ, et al. An epidemic of chronic kidney disease in Central America: an overview. Postgrad Med J 2013;89:123-5.

6. Wang H, Naghavi M, Allen C, et al. GBD 2015 Mortality and Causes of Death Collaborators. Global, regional, and national life expectancy, all-cause mortality, and cause-specific mortality for 249 causes of death, 1980-2015: a systematic analysis for the Global Burden of Disease Study 2015. Lancet 2016;388:1459-544.

7. Ellam T, Twohig H, Khwaja A. Chronic kidney disease in elderly people: disease or disease label? BMJ 2016;6559:h6559.

8. Rikkert MG, Melis RJ, Claassen JA. Heat waves and dehydration in the elderly. BMJ 2009;339:b2663.

9. Flynn A, McGreevy C, Mulkerrin EC. Why do older patients die in a heatwave? QJM 2005;98:227-9.

10. de Lorenzo A, Liaño F. High temperatures and nephrology: the climate change problem. Nefrologia 2017;37:492-500.

11. Lloyd EL. ABC of sports medicine. Temperature and performance--II: Heat. BMJ 1994;309:587-9.

12. Roncal-Jimenez C, Lanaspa MA, Jensen T, et al. Mechanisms by which dehydration may lead to chronic kidney disease. Ann Nutr Metab 2015;66 Suppl 3:10-13.

13. Roncal-Jimenez C, García-Trabanino R, Barregard L, et al. Heat stress nephropathy from exercise-induced uric acid crystalluria: a perspective on mesoamerican nephropathy. Am J Kidney Dis 2016;67:20-30.

14. Roncal Jimenez CA, Ishimoto T, Lanaspa MA, et al. Fructokinase activity mediates dehydration-induced renal injury. Kidney Int 2014;86:294-302.

15. Brooks DR, Ramirez-Rubio 0, Amador JJ. CKD in Central America: a hot issue. Am J Kidney Dis 2012;59:481-4.

16. Jayasumana C, Gunatilake S, Senanayake P. Glyphosate, hard water and nephrotoxic metals: are they the culprits behind the epidemic of chronic kidney disease of unknown etiology in Sri Lanka? Int J Environ Res Public Health 2014;11:2125-47.

17. Rampazzo N, Rampazzo Todorovic G, Mentler A, et al. Adsorption of glyphosate and aminomethylphosphonic acid in soils. Int Agrophys 2013;27:203-9.

18. Ayoola S. Histopathological effects of glyphosate on juvenile african catfish (clarias gariepinus). American-Eurasian Journal of Agricultural \& Environmental Sciences 2008;4:362-7.

19. González-Quiroz M, Pearce N, Caplin B, et al. What do epidemiological studies tell us about chronic kidney disease of undetermined cause in Meso-America? A systematic review and meta-analysis. Clin Kidney J 2018;11:496-506.

20. Kupferman J, Ramírez-Rubio 0, Amador JJ, et al. Acute kidney injury in sugarcane workers at risk for mesoamerican nephropathy. Am J Kidney Dis 2018.

21. Gonzalez-Quiroz M, Smpokou ET, Silverwood RJ, et al. Decline in kidney function among apparently healthy young adults at risk of mesoamerican nephropathy. J Am Soc Nephrol 2018;29:2200-12.

22. Bhaskaran K, Armstrong B, Hajat S, et al. Heat and risk of myocardial infarction: hourly level case-crossover analysis of MINAP database. BMJ 2012;345:e8050.

23. Centers for Disease Control and Prevention (CDC). Heat-related mortality-Chicago, July 1995. MMWR Morb Mortal Wkly Rep 1995;44:577-9.

24. Wegman DH, Apelqvist J, Bottai M, et al. Intervention to diminish dehydration and kidney damage among sugarcane workers. Scand $J$ Work Environ Health 2018;44:16-24. 
25. Bodin T, García-Trabanino R, Weiss I, et al. Intervention to reduce heat stress and improve efficiency among sugarcane workers in El Salvador: Phase 1. Occup Environ Med 2016;73:409-16.
26. U.S. Department of Health and Human Services. Centers for Disease Control and Prevention, National Institute for Occupational Safety and Health. NIOSH criteria for a recommended standard: occupational exposure to heat and hot environments. Cincinnati: NIOSH, 2016. 